\title{
Effects of Light Quality on the Chlorophyll Degradation Pathway in Rice Seedling Leaves
}

\author{
Chang-Chang $\mathrm{CHEN}^{1}$, Kuan-Hung LIN², Meng-Yuan HUANG ${ }^{2}$, \\ Wen-Dar HUANG ${ }^{3 * *}$, Chi-Ming YANG ${ }^{4 *}$ \\ ${ }^{1}$ Miaoli District Agricultural Research and Extension Station, Council of Agriculture, Gongguan township 36346, Miaoli County, \\ Taiwan; ccchen@mdais.gov.tw \\ ${ }^{2}$ Chinese Culture University, Department of Horticulture and Biotechnology, 11114 Taipei, \\ Taiwan; rlin@faculty.pccu.edu.tw; bmy6@ulive.pccu.edu.tw \\ ${ }^{3}$ National Taiwan University,Department of Agronomy,Daan 10617,Taipei, Taiwan; wendar@ntu.edu.tw (**co-corresponding author) \\ ${ }^{4}$ Academia Sinica, Biodiversity Research Center, Nankang 11529, Taipei, Taiwan; cmyang@gate.sinica.edu.tw (*correspondingauthor)
}

\begin{abstract}
The objective of this study was to investigate the dynamics of chlorophyll (Chl), biosynthetic intermediates (protoporphyrin IX, magnesium protoporphyrin IX, and protochlorophyllide), degradation intermediates [chlorophyllide (Chlide), pheophytin (Phe), and pheophorbide (Pho)], and carotenoids (Car) in leaves of rice seedlings. Two rice varieties, 'Taichung Shen 10' ('TCS10') and 'IR1552', were grown under different light quality conditions controlled by light emitting diodes (LED). Lighting treatments for rice seedlings were included by red (R), blue (B), green (G), and red + blue (RB), with fluorescent lighting (FL) as the control and photosynthetic photon flux density being set at $105 \mu \mathrm{mol} \mathrm{m} \mathrm{m}^{-2} \mathrm{~s}^{-1}$. The results show that lower levels of $\mathrm{Chl}$ and $\mathrm{Car}$ in leaves were detected under G lighting, and light quality did not mediate porphyrins in biosynthetic pathways. Rice seedling leaves took $\mathrm{Chl} \rightarrow \mathrm{Phe} \rightarrow \mathrm{Pho}$ and $\mathrm{Chl} \rightarrow \mathrm{Chlide} \rightarrow \mathrm{Pho}$ as the major and minor degradation routes, respectively. Furthermore, higher Phe/Chlide ratios were observed under G and FL lighting conditions, indicating that green-enriched environments can up-regulate the minor degradation route in leaves.
\end{abstract}

Keywords: biosynthesis and degradation pathways, light quality, rice

\section{Introduction}

Light is the photosynthetic energy source and used as an environmental factor that triggers plant morphogenesis and developments. Plant development is strongly influenced by light quality, which refers to the composition of spectrum or wavelengths reaching a plant (Johkan et al., 2010; Bian et al., 2015). Red and blue lights have the greatest impact on plant growth because they are the major energy sources for $\mathrm{CO}_{2}$ assimilation in plant. It is well known that spectra have action maxima in the blue and red ranges (Kasajima et al., 2008). The quality, duration, and intensity of red light/far red light, blue light, UV-A (320-500 nm) or UV-B (280-320 nm) are related to plant hormone signaling pathways that have a profound influence on plant by triggering or halting physiological reactions and controlling the growth and development of plant (Clouse, 2001; Shin et al., 2008; Montgomery, 2016). The functions of green light on the morphogenesis, metabolism, and photosynthesis of plants have been investigated extensively (Kasajima et al., 2008; Zhang et al., 2011; Johkan et al., 2012).
Chlorophylls (Chl) and carotenoids (Car) are photosynthetic pigments in plants. The Chl biosynthesis and/or degradation pathway influences Chl accumulation. Light induces the Chl biosynthesis pathway, and different spectrums influence the formation of photosynthetic pigments (Jilani et al., 1996; Hoober et al., 1999; Su et al., 2014). Blue light induces higher Chl $a / b$ ratios (Rivkin, 1989; Demarsac et al., 1993; Chen et al., 2014; Hoffmann et al., 2015) and greater accumulations of Chl (Kurilčik et al., 2008; Poudel et al., 2008; Hoffmann et al, 2016). Red light inhibits Chl synthesis at lower concentrations of $\mathrm{Chl}$ and precursors like 5aminolevulinic acid (Tanaka et al., 1998; Sood et al., 2005), protoporphyrin IX (PPIX), magnesium protoporphyrin IX (MGPP), and protochlorophyllide (Pchlide) (Fan et al., 2013). Moreover, the mole percentages of PPIX, MGPP, and Pchlide also respond to various physiological conditions and genotypes (Hsu et al., 2003; Hsu et al., 2011; Huang et al., 2014).

Chlorophyllase and Mg-dechelatase actions, which are responsible for the first steps in the Chl degradation pathway, are elicited by Rhopalosiphum padi and Diuraphis noxia (Ni et 
394

al., 2002; Wang et al., 2004). Chlorophyllase 1 of Arabidopsis thaliana, encoded by $A t C L H 1$, is indicated to be involved in plant damage control, and can modulate the balance between different plant defense pathways (Kariola et al., 2005). Previously, we found that the leaves of sweet potato (Hsu et al., 2003) and Machilus thunbergii (Yang et al., 2003) use $\mathrm{Chl} \rightarrow$ pheophytin (Phe) $\rightarrow$ pheophorbide (Pho) as the major route for $\mathrm{Chl}$ degradation, whereas the leaves of banana might use $\mathrm{Chl} \rightarrow$ chlorophyllide (Chlide) $\rightarrow$ Pho as the major route (Hsu et al., 2011). In addition, some biotic/abiotic factors also affect the degradation pathway (Hsu et al., 2003; Yang et al., 2003; Hsu et al., 2011; Huang et al., 2014). However, there are no reports describing the effects of LED lighting on the Chl degradation pathway. Our objective was to investigate Chl biosynthetic and degradation pathways in leaves of rice seedlings grown under different lighting spectra.

\section{Materials and Methods}

\section{Plant materials and growth conditions}

Rice (Oryza sativa L.) cultivars 'IR1552' with purple leaves and 'Taichung Shen 10' ('TCS10', green leaf), one of the most widely grown rice cultivars in Taiwan, were used in this study. Seeds were sterilized with $2 \%$ sodium hypochlorite for $20 \mathrm{~min}$, washed extensively with distilled water, and germinated in Petri dishes on wetted filter paper at $37^{\circ} \mathrm{C}$ in the dark. After $48 \mathrm{~h}$ of incubation, uniformly germinated seeds were selected and cultivated in a $150 \mathrm{ml}$ beaker containing a half-strength Kimura B nutrient solution with the following macro and microelements: $182.3 \mu \mathrm{M}\left(\mathrm{NH}_{4}\right)_{2} \mathrm{SO}_{4}, 91.6 \mu \mathrm{M} \mathrm{KNO}_{3}, 273.9$ $\mu \mathrm{M} \mathrm{MgSO} 4.7 \mathrm{H}_{2} \mathrm{O}, 91.1 \mu \mathrm{M} \mathrm{KH}_{2} \mathrm{PO}_{4}, 182.5 \mu \mathrm{M} \mathrm{Ca}\left(\mathrm{NO}_{3}\right)_{2}$, $30.6 \mu \mathrm{M}$ Fe-citrate, $0.25 \mu \mathrm{M} \mathrm{H}_{3} \mathrm{BO}_{3}, 0.2 \mu \mathrm{M} \mathrm{MnSO}_{4} \mathrm{H}_{2} \mathrm{O}, 0.2$ $\mu \mathrm{M} \mathrm{ZnSO} 4.7 \mathrm{H}_{2} \mathrm{O}, 0.05 \mu \mathrm{M} \mathrm{CuSO}_{4} .5 \mathrm{H}_{2} \mathrm{O}$, and $0.07 \mu \mathrm{M}$ $\mathrm{H}_{2} \mathrm{MoO}_{4}$. Nutrient solutions ( $\mathrm{pH} 4.7$ ) were replaced every $3 \mathrm{~d}$. Hydroponically cultivated rice seedlings were raised in growth chambers with the LED lighting at $30^{\circ} \mathrm{C}$ and $25^{\circ} \mathrm{C}$ for day and night, respectively, under a $12 \mathrm{~h}$ photoperiod.

\section{Light treatments}

LED lighting systems with a digital controller designed by GRE Technology (Taipei, Taiwan) were used to control light quality. Spectral distributions of blue (peak at $460 \mathrm{~nm}$ ), red (peak at $630 \mathrm{~nm}$ ), and green (peak at $530 \mathrm{~nm}$ ) were measured using a spectroradiometer (LI-COR1800, Lincoln, NE, USA) in the 300-800 $\mathrm{nm}$ range. Light treatments for rice seedlings, proliferation, and differentiation consisted of red LED (R), blue LED $(B)$, green LED $(G)$, a mixture of red plus blue LEDs $(\mathrm{R}: \mathrm{B}=4: 1$ by photon flux density; $\mathrm{RB}$ ), and fluorescent lighting (FL, control). Photosynthetic photon flux density (PPFD) was uniformly set at $105 \mu \mathrm{mol} \mathrm{m}^{-2} \mathrm{~s}^{-1}$. The experiment was independently performed three times under randomized growth conditions, and measurements representing the means of nine plants (three replications consisting of three plants each) were taken.

\section{Pigment analysis}

All hydroponic seedlings were collected on day 14 after reaching stage V2 or V3 according to Counce et al. (2000). The second fully expanded leaves of the seedlings were detached, frozen with liquid nitrogen, and extracted with $80 \%$ acetone.
The concentrations of Car, less polar (LP) Car, more polar (MP) Car, and Chl-related compounds (i.e., PPIX, MGPP, Pchlide, Chl, Chlide, and Phe) were determined according to Yang et al. (1998) with a spectrophotometer (Hitachi U3010, Tokyo, Japan). The mole percent of individual porphyrin is defined as [(PPIX, MGPP or Pchlide) / (PPIX + MGPP + Pchlide) $x$ x 100\%. The values of phytylated and/or dephytylated pigments in samples were read directly at absorbances of 661 and $666 \mathrm{~nm}\left(\mathrm{~A}_{661}\right.$ and $\left.\mathrm{A}_{666} \mathrm{~g}^{-1} \mathrm{DW}\right)$, respectively. The value of $\mathrm{A}_{661}$ cannot be transformed into individual content of Chl and Phe, however, it can be used to compare the relative content of total phytylated pigments (Shioi and Sasa, 1986). On the other hand, the value of $A_{666}$ also can be used to compare the relative content of total dephytylated pigments (Chlide and Pho).

\section{Statistical analyses}

All measurements were evaluated for significance using an analysis of variance (ANOVA) followed by a least significant difference (LSD) test at the $p<0.05$ level. All statistical analyses were conducted using SAS 9.3 (SAS Institute; Cary, NC, USA).

\section{Results}

\section{Chland Car}

The dynamics of photosynthetic pigments in leaves of both cultivars under different lighting qualities are listed in Table 1. The concentrations of Chl and Car in leaves of 'IR1552' were higher than those of 'TCS10'. In both cultivars, the concentration of $\mathrm{Chl}$ was lower under $\mathrm{G}$ lighting, but $\mathrm{Chl}$ concentrations among $\mathrm{B}, \mathrm{BR}$, and $\mathrm{FL}$ treatments were not significantly different. A similar trend was observed in Car in the leaves of TCS10, but there were no significant differences with IR1552.

Concentrations of LP Car were dramatically reduced in leaves of both cultivars under $G$ condition. A lower accumulation of LP Car was also observed in leaves of 'TCS10' under FL (369 $\left.\mathrm{ug} \mathrm{g}^{-1} \mathrm{DW}\right)$. Significantly lower concentrations of MP Car were observed in leaves of 'TCS10' under G and R lightings. However, the effects of LED lighting were insignificant on MP Car in 'IR1552'. Light quality influenced LP Car/MP Car ratios in 'TCS10' strongly, but not in IR1552.

\section{Porphyrins and their mole percentages}

Porphyrins are the Chl biosynthesis intermediates. The accumulation of porphyrins in leaves of 'IR1552' was higher than those in 'TCS10' (Fig. 1). The concentration of porphyrins in TCS10 was not significantly different among all treatments $\left(2.84 \sim 3.13 \mu \mathrm{mol} \mathrm{g} \mathrm{g}^{-1} \mathrm{DW}\right)$. IR1552 showed a similar response, but the levels of porphyrins under $\mathrm{B}$ were lower than in other treatments. The percentages of PPIX and MGPP were insignificant among all lighting conditions for both cultivars (Fig. 2). The percentage of Pchlide in 'TCS10' was higher compared with other treatments, and it was irresponsive to lighting quality in 'IR1552'.

\section{Chl degradation intermediates}

The concentration of Phe was higher than Chlide for both cultivars (Fig. 3). Leaves of rice seedlings took $\mathrm{Chl} \rightarrow \mathrm{Phe} \rightarrow \mathrm{Pho}$ as the major degradation route, but $\mathrm{Chl} \rightarrow \mathrm{Chlide} \rightarrow \mathrm{Pho}$ as the 
Table 1. Effects of light quality on the levels of Chl (express in $\mathrm{mg} \mathrm{g}^{-1} \mathrm{DW}$ ), Car, LP Car, MP Car (expressed in $\mu \mathrm{g} \mathrm{g}{ }^{-1} \mathrm{DW}$ ), and their ratios in seedling leaves collected from 14-d seedlings under different lighting environments

\begin{tabular}{|c|c|c|c|c|c|c|}
\hline Variety & $\begin{array}{c}\text { Light } \\
\text { treatment* }\end{array}$ & Chl & Car & LP Car & MP Car & $\mathrm{LP} / \mathrm{MP}$ \\
\hline \multirow{5}{*}{ 'TCS10' } & FL & $12.08 \mathrm{c}$ & $4.55 \mathrm{~cd}$ & $369 \mathrm{de}$ & $575 a$ & $0.64 \mathrm{c}$ \\
\hline & $\mathrm{R}$ & $10.6 \mathrm{~d}$ & $4.2 \mathrm{de}$ & 400 cde & $377 b$ & $1.06 \mathrm{a}$ \\
\hline & G & $9.67 \mathrm{~d}$ & $3.88 \mathrm{e}$ & $342 \mathrm{e}$ & $348 \mathrm{~b}$ & $0.98 \mathrm{ab}$ \\
\hline & B & $12.96 \mathrm{bc}$ & $4.88 \mathrm{bc}$ & 394 de & $544 \mathrm{a}$ & $0.79 \mathrm{bc}$ \\
\hline & $\mathrm{RB}$ & $12.75 c$ & $4.63 c$ & $446 \mathrm{~cd}$ & $518 a$ & $0.90 \mathrm{abc}$ \\
\hline \multirow{5}{*}{ 'IR1552’ } & FL & $15.01 \mathrm{a}$ & $5.49 a$ & $593 a$ & $604 a$ & $0.99 \mathrm{ab}$ \\
\hline & $\mathrm{R}$ & $14.16 \mathrm{ab}$ & $5.23 \mathrm{ab}$ & $554 \mathrm{ab}$ & $541 \mathrm{a}$ & $1.02 \mathrm{ab}$ \\
\hline & G & $12.63 \mathrm{c}$ & $4.93 \mathrm{bc}$ & $486 b c$ & $500 a$ & $0.97 \mathrm{ab}$ \\
\hline & B & $14.27 \mathrm{a}$ & $4.95 \mathrm{bc}$ & $543 a b$ & $511 \mathrm{a}$ & $1.06 \mathrm{a}$ \\
\hline & $\mathrm{RB}$ & $15.35 \mathrm{a}$ & $5.2 \mathrm{ab}$ & $613 a$ & $584 \mathrm{a}$ & $1.05 \mathrm{ab}$ \\
\hline
\end{tabular}

Within columns, means followed by the same letter are not significantly different according to LSD $(p<0.05)$

$\mathrm{Chl}$ - chlorophyll; Car - carotenoids; LP - less polar; MP - more polar; R - red; B - blue; G - green; RB - mixture of red plus blue; FL - fluorescent lighting

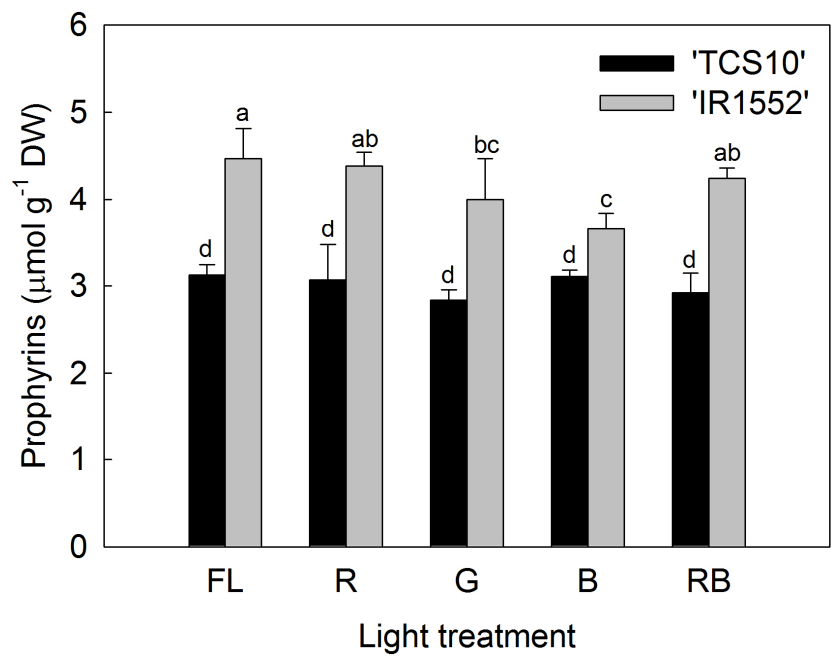

Fig. 1. Means $\pm S E$ of prophyrins of leaves collected from 14-d seedlings under different lighting environments. The values followed by the different letter show statistically significant differences at $p<0.05$. R - red; B - blue; G - green; RB mixture of red plus blue; FL - fluorescent lighting

minor degradation route. In both cultivars, the concentrations of Phe under $\mathrm{G}$ were lower than in other treatments, and the highest concentration of Phe was under RB. The concentration of Chlide under FL was greater than in other treatments. The Phe/Chlide ratios of 'IR1552' under G and FL were lower than other treatments (insignificant at $p<0.05$ ). A similar trend was observed in 'TCS10', with the exception of G. The results of phytylated and dephytylated pigments and their ratios were also shown a similar trend to the Phe/Chlide ratio (Fig. 4).

\section{Discussion}

Plant pigments have specific wavelength absorption patterns known as absorption spectra. Biosynthetic wavelengths for the production of plant pigments are referred to as action spectra (Wang et al., 2009). Chls have high light absorptions at 400-500 and 630-680 nm, and Cars have high light absorptions at 400-500. Meanwhile, both Chls and Cars

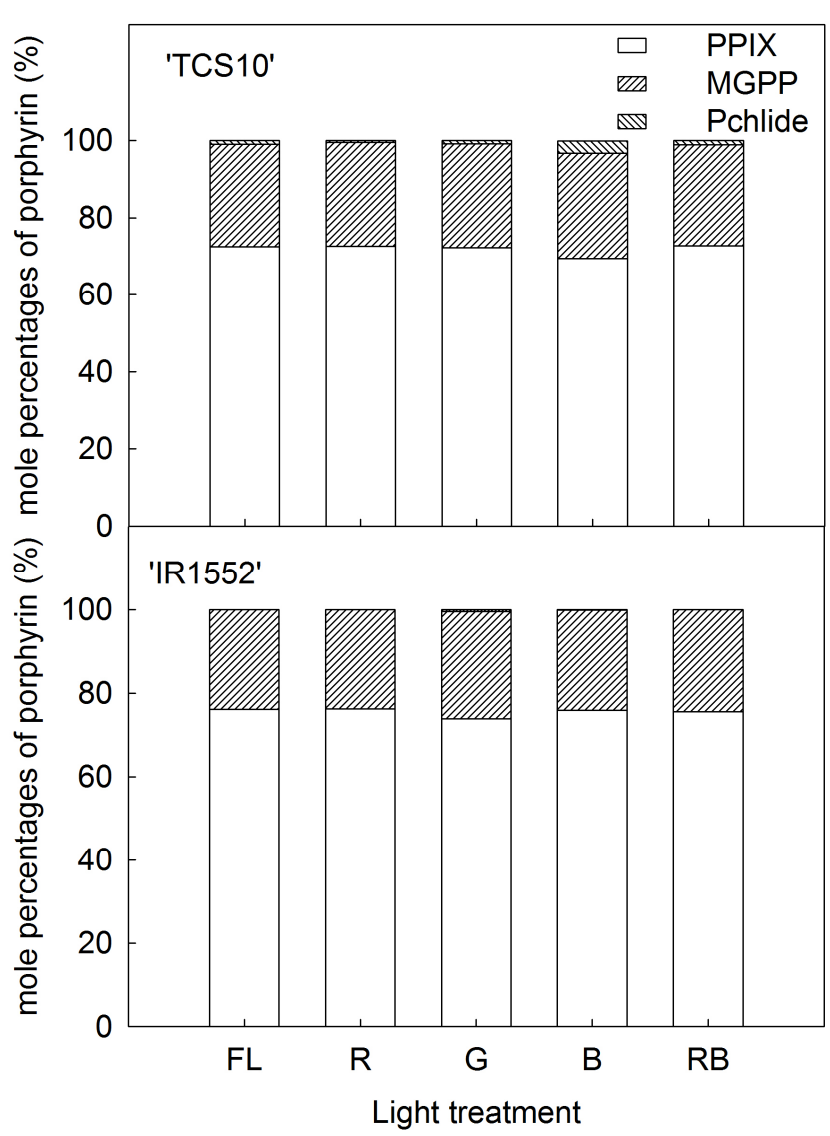

Fig. 2. The mole percentages of protoporphyrin IX (PPIX), magnesium protoporphyrin IX (MGPP), and protochlorophyllide (Pchlide) in leaves collected from 14-d seedlings of 'TCS10' and 'IR1552'under different lighting environments. R - red; B - blue; G - green; RB - mixture of red plus blue; FL - fluorescent lighting

have low light absorption at 530-610 nm. Previous studies (Nhut et al., 2003; Lee et al., 2007; Johkan et al., 2010; Guo et al., 2011; Lin et al., 2011; Liu et al., 2011; Fan et al., 2013, Hoffmann et al., 2015; Hoffmann et al., 2016) have demonstrated that blue light induced the synthesis of $\mathrm{Chl}$ and Car. In our study, the concentrations of $\mathrm{Chl}$ and Car were greater under FL, B, and RB treatments, with the exception of 
396

IR1552 under B lighting, and were lower under G lighting (Table 1). However, our previous study showed that Car levels were not responsive to light quality (Chen et al., 2014). These different results under the same experimental conditions, including light quality and rice variety, might be due to the change in light irradiance with higher light irradiance (160 $\mu$ mole $\mathrm{m}^{-2} \mathrm{~s}^{-1}$ ), resulting in insignificant differences in Car levels. MP and LP Car levels respond to different aging and senescent conditions (Hsu et al., 2003). MP Car levels decrease as LP Car levels increase during the maturation/ageing process. Our results show that MP and LP Car levels were also mediated by

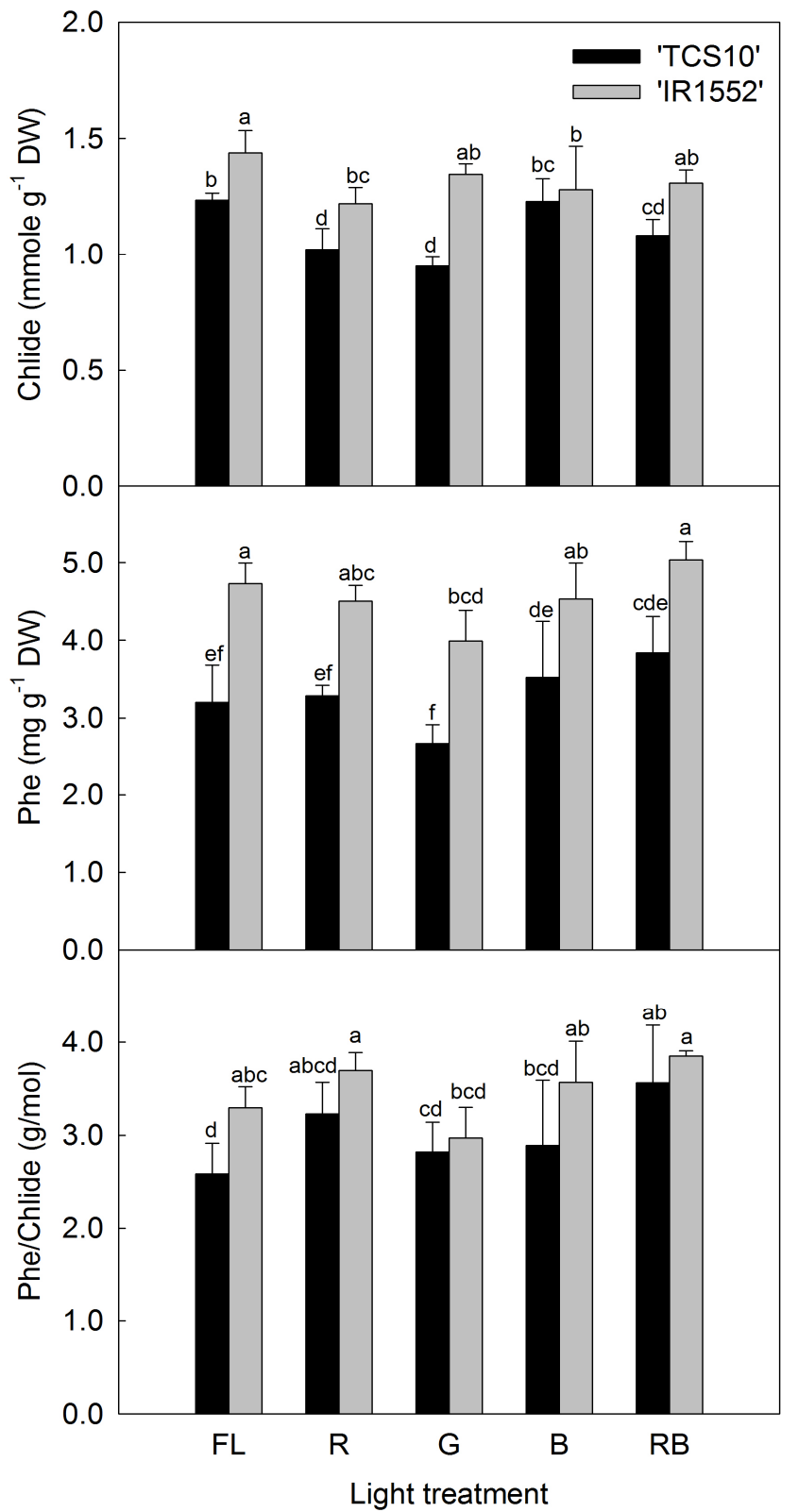

Fig. 3. Means $\pm S E$ of chlorophyllide (Chlide), pheophytin (Phe), and their ratios in 14-d seedling leaves under different lighting environments. The values followed by the different letter show statistically significant differences at $p<0.05$. R red; B - blue; G - green; RB - mixture of red plus blue; FL fluorescent lighting light quality; including the possibility that green light inhibited LP Car synthesis.

Light is an important environmental signal and induces chlorophyll biosynthesis (Jilani et al., 1996). Chl reduction was observed under red light as a result of a decrease in aminolevulinic acid (Tanaka et al., 1998; Sood et al., 2005), PPIX, MGPP, and Pchlide (Fan et al., 2013). In our study, porphyrin levels were not reduced by red light (Fig. 1). The mole percentages of PPIX, MGPP, and Pchlide are responsive to maturing/aging in sweet potato leaves (Hsu et al., 2003), and tissues infected by disease/insects (Hsu et al., 2011; Huang et

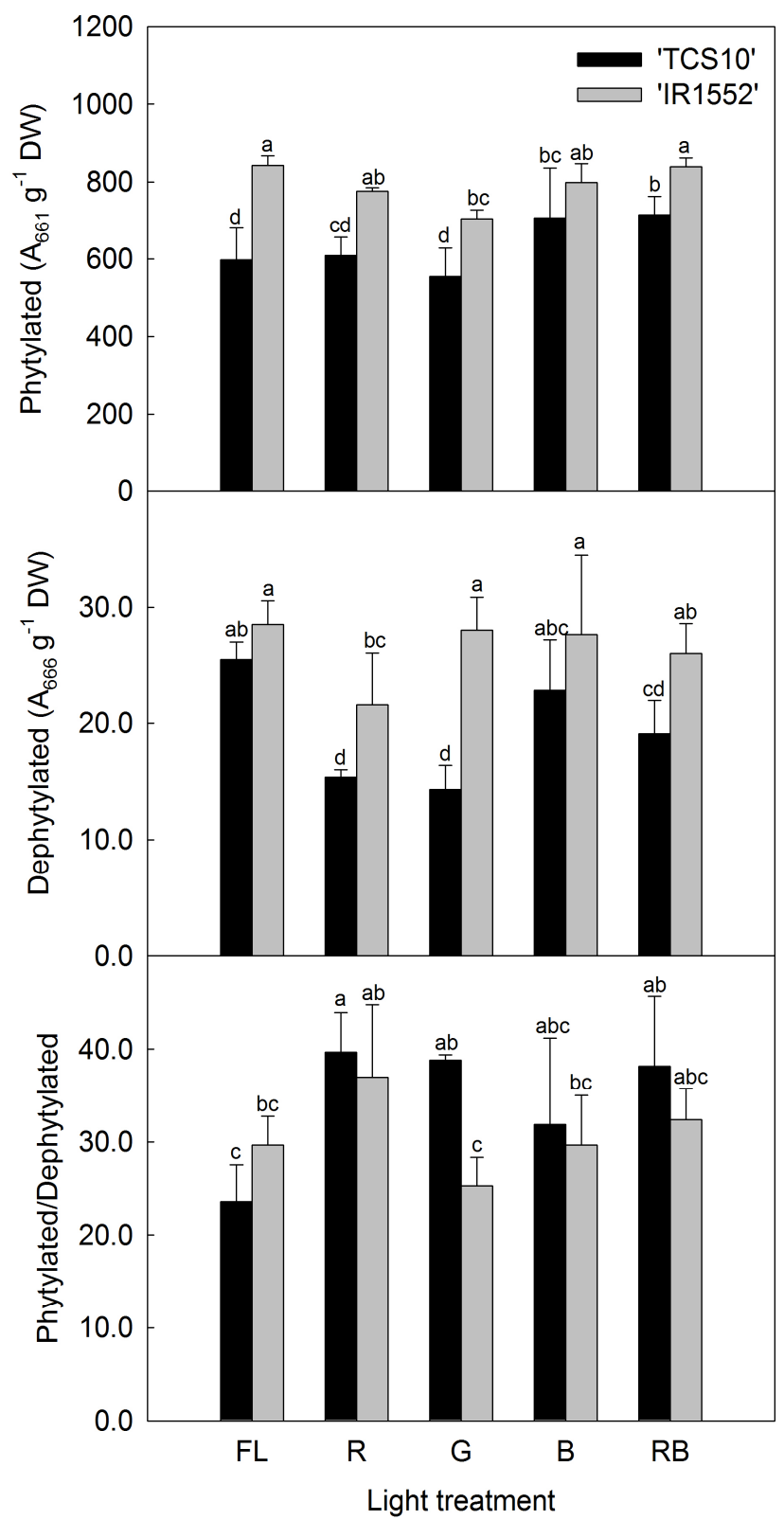

Fig. 4. Means $\pm S E$ of phytylated (expressed in $A_{661} g^{-1} D W$ ) and dephytylated (expressed in $\mathrm{A}_{666} \mathrm{~g}^{-1} \mathrm{DW}$ ) pigments and their ratios in 14-d seedling leaves under different lighting environments. The values followed by the different letter show statistically significant differences at $p<0.05$. R - red; B - blue; $\mathrm{G}$ - green; RB - mixture of red plus blue; FL - fluorescent lighting 
al., 2014). Light quality also influences the mole percentages of these three precursors. According to Fan et al. (2013), green light increases the mole percentage of PPIX but decreases the mole percentage of MGPP and Pchlide. Nevertheless, our results demonstrate that the mole percentages of the three precursors were insignificant among all treatments except for 'TCS10' under B, and Chl biosynthetic intermediates under light quality did not affect the Chl biosynthetic pathway (Fig. 2). The removal of $\mathrm{Mg}$ or the phytol chain, catalyzed by Mgdechelatase and chlorophyllase, respectively, are the two possible routes in the initial period of Chl degradation. Their products are Chlide and Phe, respectively, which are further converted into Pho and continue to degrade into even smaller molecules (Matile et al., 1996). The four products in the initial period of Chl degradation can be divided into two categories according to their chemical structures. The first category contains phytylated pigments, such as $\mathrm{Chl}$ and Phe, all of which contain a phytol chain in their structure, but the first example contains $\mathrm{Mg}$ while the second does not. The other category contains dephytylated pigments, including Chlide and Pho, but the first contains Mg while the second does not (Matile $e t$ al., 1996).

Sweet potato, rice, and Machilus thunbergii use $\mathrm{Chl} \rightarrow \mathrm{Phe} \rightarrow \mathrm{Pho}$ and $\mathrm{Chl} \rightarrow \mathrm{Chlide} \rightarrow \mathrm{Pho}$ as the major and minor routes for chlorophyll degradation, respectively (Hus et al., 2003; Huang et al., 2014). Some physiological conditions, such as aging (Hsu et al., 2003), disease (Hsu et al., 2011), and infestation by insects (Huang et al., 2014), are important factors for mediating the ratio between these two routes and phytylated and dephytylated pigments. In our study, rice seedlings also took $\mathrm{Chl} \rightarrow \mathrm{Phe} \rightarrow$ Pho as the major route (Fig. 3). A lower Phe/Chlide ratio under $\mathrm{G}$ lighting was observed among three mono-spectrum lighting conditions, and the ratio under FL was also lower between the two poly-spectrum lighting conditions. Furthermore, higher levels of Chlide were generally apparent under G and FL in the study. Phytylated/dephytylated ratios showed similar trends (Fig. 4). These results suggest that a green light-enriched environment might promote the minor route for $\mathrm{Chl}$ degradation. This phenomenon warrants further investigation.

\section{Conclusions}

Light quality not only influences the accumulation of photosynthetic pigments, but also mediates the $\mathrm{Chl}$ degradation pathway in rice seedling leaves, possibly promoting the minor route of Chl degradation in rice seedling leaves.

\section{Acknowledgements}

We thank Dr. Su-Jein Chang (Miaoli District Agricultural Research and Extension Station) and Dr. Zhi-Wei Yang (Taoyuan District Agricultural Research and Extension Station) for donation of 'IR1552' and 'TCS10' seeds.

\section{References}

Bian ZH, Yang QC, Liu WK (2015). Effects of light quality on the accumulation of phytochemicals in vegetables produced in controlled environments: a review. Journal of the Science of Food and Agriculture 95:869-877.
Chen CC, Huang MY, Lin KH, Wong SL, Huang WD, Yang CM (2014). Effects of light quality on the growth, development and metabolism of rice seedlings (Oryza sativa L.). Research Journal of Biotechnology 9:15-24.

ClouseSD (2001). Integration of light and brassinosteroid signals in etiolated seedlinggrowth. Trends in PlantScience 6:443-445.

Counce PA, Keisling TC, Mitchell AJ (2000). A uniform, objective, and adaptive system for expressing rice development. Crop Science 40:436443.

Demarsac NT, Houmard J (1993). Adaptation of cyanobacteria to environmental stimuli - new steps towards molecular mechanisms. Fems Microbiology Letters 104:119-189.

Fan X,ZangJ,Xu Z, GuoS, Jiao X, Liu X, Gao Y (2013). Effects of different light quality on growth, chlorophyll concentration and chlorophyll biosynthesis precursors of non-heading Chinese cabbage (Brassica campestris L.). Acta Physiologiae Plantarum 35:2721-2726.

Guo RQ, Ruan H, Yang WJ, Liu B, Sun SC (2011). Differential responses of leaf water-use efficiency and photosynthetic nitrogen-use efficiency to fertilization in Bt-introduced and conventional rice lines. Photosynthetica 49:507-514.

Hoffmann AM, Noga G, Hunsche M (2015). Acclimations to light quality on plant and leaf level affect the vulnerability of pepper (Capsicum annum $\mathrm{L}$.) to water deficit.Journal of Plant Research 128:295-306.

Hoffmann AM, Noga G, Hunsche M (2016). High blue light improves acclimation and photosynthetic recovery of pepper plants exposed to UV stress. Environmental and Experimental Botany 109:254263.

Hoober JK, Eggink LL (1999). Assembly of light-harvesting complex II and biogenesis of thylakoid membranes in chloroplasts. Photosynthesis Research 61:197-215.

Hsu MH, Huang WD, YangZW, Tsai YZ, Yang CM, Chang SS (2003). Study on the chlorophyyll biosynthetic and degradative pathway in the leaves of three sweet potatoes. Chinese Agronomy Journal 3:87-98.

Hsu MH, Yang ZW, Huang WD, Yang CM (2011). Study on the chlorophyll biosynthetic and degradative pathway in the leaves of banana infected with Fusarium Wilt. Scientific Agriculture, Taiwan 59:21-28.

Huang MY, Huang WD, Chou HM, Chen CC, Chang YT, Yang CM (2014). Herbivorous insects alter the chlorophyll biosynthetic and degradation pathway of galls on host plant. Journal of Asia-Pacific Entomology 17:431-434.

Jilani A, Kar S, Bose S, Tripathy BC (1996). Regulation of the carotenoid content and chloroplast development by levulinic acid. Physiologia Plantarum 96:139-145.

Johkan M, Shoji K, Goto F, Hahida S, Yoshihara T (2012). Effect of green light wavelength and intensity on photomorphogenesis and photosynthesis in Lactuca sativa. Environmental and Experimental Botany 75:128-133.

Johkan M, Shoji K, Goto F, Hashida S, Yoshihara T (2010). Blue lightemitting diode light irradiation of seedlings improves seedling quality and growth after transplanting in red leaf lettuce. HortScience 45:18091814.

Kariola T, Brader G, Li J, Palva ET (2005). Chlorophyllase 1, a damage control enzyme, affects the balance between defense pathways in plants. PlantCell 17:282-294. 
398

Kasajima S, Inoue N, Mahmud R, Kato M (2008). Developmental responses of wheat cr. Norin 61 to fluence rate of green light. Plant Production Science 11:76-81.

Kurilčik A, Miklušyte-Čanova R, Dapkūnienè S, Žilinskaite S, Kurilčik G, Tamulaitis G, Duchovskis P, Žukauskas A (2008). In vitro culture of Chrysanthernum plantlets using light-emitting diodes. Central European Journal of Biology 3:161-167.

Lee SH, Tewari RK, Hahn EJ, Paek KY (2007). Photon flux density and light quality induce changes in growth, stomatal development, photosynthesis and transpiration of Withania somnifera (L.) Dunal. plantlets. Plant Cell, Tissue and Organ Culture 90:141-151.

Lin Y,LiJ,LiB, He T, ChunZ(2011).Effects of light quality on growth and development of protocorm-like bodies of Dendrobium officinale in vitro. Plant Cell, Tissue and Organ Culture 105:329-335.

Liu MX, Xu ZG, Yang Y, Feng YJ (2011). Effects of different spectral lights on Oncidium PLBs induction, proliferation, and plant regeneration. Plant Cell, Tissue and Organ Culture 106:1-10.

Matile P, Hortensteiner S, Thomas H, Krautler B (1996). Chlorophyll breakdown in senescent leaves. Plant Physiology 112:1403-1409.

Montgomery BL (2016). Spatiotemporal phytochrome signaling during photomorphogenesis: from physiology to molecular mechanisms and back. Frontiers in Plant Science 7:480-488.

Nhut DT, Takamura T, Watanabe H, Okamoto K, Tanaka M (2003). Responses of strawberry plantlets cultured in vitro under superbright red and blue light-emitting diodes (LEDs). Plant Cell, Tissue and Organ Culture73:43-52.

Ni XZ, Quisenberry SS, Heng-Moss T, Markwell J, Higley L, Baxendale F, Sarath G, Klucas R (2002). Dynamic change in photosynthetic pigments and chlorophyll degradation elicited by cereal aphid feeding. Entomologia Experimentalis Et Applicata 105:43-53.

Poudel PR, Kataoka I, Mochioka R (2008). Effect of red- and blue-lightemitting diodes on growth and morphogenesis of grapes. Plant Cell, Tissue and Organ Culture 92:147-153.

Rivkin RB (1989). Influence of irradiance and spectral quality on the carbon metabolism of phytoplankton, photosynthesis, chemical-composition and growth. Marine Ecology Progress Series 55:291-304.
Shin KS, Murthy HN, Heo JW, Hahn EJ, Paek KY (2008). The effect of light quality on the growth and development of in vitro cultured Doritaenopsis plants. Acta Physiologiae Plantarum 30:339-343.

Shioi Y, Sasa T (1986). Purification of solubilized chlorophyllase from Chlorella protothecoides. Methods in Enzymology 123:421-427.

Sood S, Gupta V, Tripathy BC (2005). Photoregulation of the greening process of wheat seedlings grown in red light. Plant Molecular Biology 59:269-287.

Su N, Wu Q, Shen Z, Xia K, Cui J (2014). Effects of light quality on the chloroplastic ultrastructure and photosynthetic characteristics of cucumber seedlings. Plant Growth Regulation 73:227-235.

Tanaka A, Ito H, Tanaka R, Tanaka NK, Yoshida K, Okada K (1998). Chlorophyll a oxygenase (CAO) is involved in chlorophyll b formation from chlorophyll a. Proceedings of the National Academy of Sciences of the United States of America 95:12719-12723.

Wang H, Gu M, Cui JX, Shi K, Zhou YH, Yu JQ (2009). Effects of light quality on $\mathrm{CO}_{2}$ assimilation, chlorophyll-fluorescence quenching, expression of Calvin cycle genes and carbohydrate accumulation in Cucumis sativus. Journal of Photochemistry and Photobiology B: Biology 96:30-37.

Wang T, QuisenberrySS, NiXZ, Tolmay V (2004). Enzymatic chlorophyll degradation in wheat near-isogenic lines elicited by cereal aphid (Homoptera aphididae) feeding. Journal of Economic Entomology 97:661-667.

Yang CM, Chang KW, Yin MH, Huang HM (1998). Methods for the determination of chlorophylls and their derivatives. Taiwania 43:116122.

Yang CM, Yang MM, Hsu JM, Jane WN (2003). Herbivorous insect causes deficiency of pigment-protein complexes in an oval-pointed cecidomyiid gall of Machilus thunbergii leaf. Botanical Bulletin of AcademiaSinica 44:315-321.

Zhang T, Maruhnich SA, Folta KM (2011). Green light induces shade avoidance symptoms. Plant Physiology 157:1528-1536. 